
Life among Frontline Otorhinolaryngology Nurses During the COVID-19 Pandemic in China: A National Survey

\title{
Zi-Rong Tian
}

Beijing Tongren Hospital

xiaomeng xie

University of Macau Faculty of Health Sciences

Xiu-Ya Li

Beijing Tongren Hospital Otolaryngology and Head and Neck Surgery Center: Beijing Tongren Hospital

Yue Li

Beijing Tongren Hospital

Qinge Zhang

Beijing An Ding Hospital

Yan-Jie Zhao

University of Macau Faculty of Health Sciences

\section{Teris Cheung}

The Hong Kong Polytechnic University

Gabor S. Ungvari

University of Western Australia Medical School

\section{Feng-Rong An}

Beijing An Ding Hospital

Yu-Tao Xiang ( $\nabla$ xyutly@gmail.com )

University of Macau, Avenida da Universidade

\section{Research}

Keywords: COVID-19, depression, otorhinolaryngology, quality of life, nurse

Posted Date: November 24th, 2020

DOI: https://doi.org/10.21203/rs.3.rs-112945/v1

License: (c) (1) This work is licensed under a Creative Commons Attribution 4.0 International License. Read Full License 


\section{Abstract}

Objective: Exposure to the coronavirus disease 2019 (COVID-19) was associated with high risk of mental health problems among frontline nurses. This study examined the prevalence of depressive symptoms (depression hereafter) and its impact on quality of life (QOL) among otorhinolaryngology (ENT) nurses during the COVID-19 pandemic in China.

Methods: A national online study was conducted between March 15 and March 20, 2020. Depression and QOL were assessed using standardized instruments.

Results: A total of 1,757 participants were recruited. The prevalence of depression was $33.75 \%$ (95\% Cl: $31.59 \%-35.97 \%$ ). Results emerging from multiple logistic regression analysis showed that direct care of COVID-19 patients (OR: 1.440, 95\% Cl: 1.031-2.012, $P=0.032$ ), and current smoker (OR: $3.143,95 \% \mathrm{Cl}$ : $1.020-9.690, P=0.046)$ were significantly associated with depression. After controlling for covariates, ENT nurses with depression had a lower overall QOL compared to those without $\left(\mathrm{F}_{(1,1757)}=536.80, P<0.001\right)$.

Conclusions: Depression was common among ENT nurses during the COVID-19 pandemic in China. Considering the negative impact of depression on QOL and care quality, regular screening for depression should be conducted among ENT nurses and timely treatments should be provided for those in need.

\section{Introduction}

The novel coronavirus disease (COVID-19) was initially emerged in Wuhan, China at the end of 2019. Since then, the disease has been transmitted to more than 200 countries, and COVID-19 has been declared a global public health emergency (World Health Organization, 2020). The reproduction number of COVID-19 ranges from 2.24 (95\%Cl: $1.96-2.55)$ to 3.58 (95\% Cl: 2.89-4.39) (Zhao et al., 2020). Similar to other respiratory viruses, this virus is mainly spread by respiratory droplets of infected cases when they speak, cough, or sneeze. In early phase of the COVID-19 outbreak, it was presumed that nosocomial transmission contributed to $41.3 \%$ of the infected patients in general, and $29 \%$ of infected health care workers (Wang et al., 2020). By nature of the clinical specialty, healthcare workers working in otorhinolaryngology (ENT) units have a much higher likelihood to have direct contacts with COVID-19 patients compared with their counterparts in other clinical specialties. ENT nurses are exceptionally susceptible to aerosolized viral particles and high viral loads in the upper respiratory tract in their daily practice. This possibly explained why many health professionals working in the ENT units were infected in early stage of the COVID-19 outbreak (Lu et al., 2020). For example, in the UK an ENT consultant was the first frontline clinician died in combating against COVID-19 on 30 March 2020 (NHS, 2020). Due to heavy clinical workload and high risk of infection, ENT nurses are more likely to suffer from mental distress, which could increase the risk of mental health problems, such as depression (Xu et al., 2020).

Depression was associated with a range of negative health outcomes, such as increased risk of suicide, lowered care quality and impaired occupational functions (Woo et al., 2016, Knight et al., 2018, Gao et al., 2019). In order to reduce the risk of depression and develop appropriate preventive measures, it is important to understand the epidemiology of depression. In addition, as a comprehensive health outcome, quality of 
life (QOL) has been gaining attention in the past decades. To date, there seemed to have no studies examining the epidemiology of depression and its impact on QOL in ENT healthcare workers. Therefore, this study was set out to examine the prevalence of depressive symptoms (depression hereafter) and its association with QOL among frontline ENT nurses in China during the COVID-19 pandemic.

\section{Methods}

\section{Setting and sample}

This was a national, cross-sectional online survey initiated by the Chinese Nursing Association Otolaryngology Branch between March 15 and March 20, 2020 in China. Due to logistic reasons and high risk of cross-infection, random sampling and face-to-face interviews were prohibited in almost all surveys involving frontline health professionals during the COVID-19 outbreak. Similar to other studies (Lai et al., 2020, Zhang et al., 2020), snowball sampling was used, and this survey was conducted using the WeChatbased Questionnaire Star program. The WeChat is a social communication application with over 1 billion users in China including all participants in this study. The Questionnaire Star program that has been widely used in many epidemiological surveys (Xi, 2017, Li, 2016, Liang and Fan, 2020). To be eligible, participants needed to be: 1) aged 18 or above; 2) frontline nurses working in the ENT unit during the COVID-19 outbreak; 3) able to understand the assessment content and provide written informed consent. The research protocol was approved by the Institutional Review Board of the University of Macau.

\section{Instruments}

Basic socio-demographic and clinical variables, such as gender, age, marital status, educational level, years of working experience, living circumstances, rank (junior or senior), hospital setting (primary or tertiary), shift duty requirement, unit nature (inpatient or outpatient department), smoking status, and experience of fighting the SARS outbreak on 2003, were collected. Three additional standardized questions were also asked using dichotomous response (yes/no): 1) whether the participant was directly engaged in clinical services for COVID-19 patients; 2) whether they had friends, colleagues, or family members infected with COVID-19; and lastly 3) the number of COVID-19 confirmed cases in the province they lived in.

The self-report Chinese version of the Patient Health Questionnaire-9 (PHQ-9) was used to measure the severity of depression. The PHQ-9 had been validated in the Chinese population with a sensitivity of 0.89 and a specificity of 0.77 (Chen, 2015). Each item scored from 0 to 3 , with the total score of $\geq 5$ indicating "having depression" (Wittkampf et al., 2007). The total score of "5-9", "10-14", "15-19", and "20-27" indicated "mild depression", "moderate depression", "moderate-to-severe depression", and "severe depression", respectively (Wittkampf et al., 2007).

QOL was measured with the first two items on overall QOL of the validated World Health Organization Quality of Life Instrument-Brief Version (WHOQOL-BREF) (Skevington et al., 2004). Higher total scores indicated higher QOL. The Chinese version of the WHOQOL-BREF has been validated in Chinese populations (Xia et al., 2012).

\section{Data analysis}


Data were analyzed with the IBM Statistical Package for Social Science (SPSS) software version 24.0. Normality of the data was assessed using the Kolmogorov-Smirnov test. Comparison between depression and no depression groups, in terms of demographic and clinical characteristics, were conducted by Chisquare tests, two samples independent sample $t$-tests and Mann-Whitney $U$ test, as appropriate. QOL was compared between the two groups using analysis of covariance (ANCOVA) after controlling the potentially confounding effects of variables with significant group difference in univariate analyses. The independent demographic and clinical correlates of depression were examined using multiple logistic regression analysis with the "Enter" method with depression as the dependent variable. All variables with a $P$-value of less than 0.1 in univariate analyses were entered as independent variables. A $P$-value of less than 0.05 was considered statistically significant (two-tailed).

\section{Results}

A total of 1,757 frontline ENT nurses participated in this study. The overall prevalence of depression was $33.75 \%$ (95\% Cl: 31.59\%-35.97\%). Among the healthcare workers with probable depression ( $N=593), 421$ (24.0\%) reported mild depression, 116 (6.6\%) moderate depression, 42 (2.4\%) moderate-to-severe depression, and $14(0.8 \%)$ severe depression. The mean total score of the PHQ-9 scale was $3.73( \pm 4.43)$ in the whole sample.

Table 1 shows the demographic and clinical characteristics of the whole sample separated by depression. Univariate analyses revealed that direct care with confirmed COVID patients $(P=0.025)$, current smoking behaviors $(P=0.033)$, and years of working experience $(P=0.020)$ were significantly associated with depression. After controlling for covariates, nurses with depression were more likely to have overall lower $\mathrm{QOL}$ than those without $\left(\mathrm{F}_{(1,1757)}=536.80, P<0.001\right)$. Multiple logistic regression analysis revealed that direct care of COVID-19 patients (OR $=1.440, P=0.032)$ and current smoking status (OR $=3.143, P=0.046)$ were independently associated with higher risk of depression (Table 2). 
Table 1

Demographic Characteristics of ENT nurses

\begin{tabular}{|c|c|c|c|c|c|c|c|c|c|}
\hline \multirow[t]{2}{*}{ Variables } & \multicolumn{2}{|c|}{$\begin{array}{l}\text { Total } \\
(\mathrm{N}=1,757)\end{array}$} & \multicolumn{2}{|c|}{$\begin{array}{l}\text { No } \\
\text { depression } \\
(N=1,164)\end{array}$} & \multicolumn{2}{|c|}{$\begin{array}{l}\text { Depression } \\
(\mathrm{N}=593)\end{array}$} & \multirow[t]{2}{*}{$x^{2}$} & \multirow[t]{2}{*}{ df } & \multirow[t]{2}{*}{$P$} \\
\hline & $\mathbf{N}$ & $\%$ & $\mathbf{N}$ & $\%$ & $\mathbf{N}$ & $\%$ & & & \\
\hline Married & 1310 & 74.6 & 875 & 75.2 & 435 & 73.4 & 0.683 & 1 & 0.409 \\
\hline $\begin{array}{l}\text { College education and } \\
\text { above }\end{array}$ & 1707 & 97.2 & 1131 & 97.2 & 576 & 97.1 & 0.001 & 1 & 0.970 \\
\hline Living with family & 1483 & 84.4 & 988 & 84.9 & 495 & 83.5 & 0.590 & 1 & 0.442 \\
\hline Junior nurses & 1017 & 57.9 & 683 & 58.7 & 334 & 56.3 & 0.892 & 1 & 0.345 \\
\hline $\begin{array}{l}\text { Experience of fighting } \\
\text { SARS }\end{array}$ & 204 & 11.6 & 136 & 11.7 & 68 & 11.5 & 0.018 & 1 & 0.893 \\
\hline $\begin{array}{l}\text { Working in tertiary } \\
\text { hospitals }\end{array}$ & 1528 & 87.0 & 1001 & 86.0 & 527 & 88.9 & 2.862 & 1 & 0.091 \\
\hline $\begin{array}{l}\text { Working in inpatient } \\
\text { department }\end{array}$ & 1535 & 87.4 & 1024 & 88.0 & 511 & 86.2 & 1.154 & 1 & 0.283 \\
\hline Shift duty nurses & 1195 & 68.0 & 789 & 67.8 & 406 & 68.5 & 0.084 & 1 & 0.772 \\
\hline $\begin{array}{l}\text { Local COVID-19 cases } \geq \\
500\end{array}$ & 235 & 13.4 & 161 & 13.8 & 74 & 12.5 & 0.620 & 1 & 0.431 \\
\hline $\begin{array}{l}\text { Having infected } \\
\text { family/friends/colleagues }\end{array}$ & 86 & 4.9 & 50 & 4.3 & 36 & 6.1 & 2.660 & 1 & 0.103 \\
\hline $\begin{array}{l}\text { Taking care of infected } \\
\text { patients }\end{array}$ & 158 & 9.0 & 92 & 7.9 & 66 & 11.1 & 4.996 & 1 & 0.025 \\
\hline \multirow[t]{2}{*}{ Current smoker } & 13 & 0.7 & 5 & 0.4 & 8 & 1.3 & 4.523 & 1 & 0.033 \\
\hline & Mean & SD & Mean & SD & Mean & SD & $\mathrm{T} / \mathrm{Z}$ & df & $P$ \\
\hline Age (years) & 34.09 & 8.03 & 33.86 & 8.23 & 34.56 & 7.62 & -1.729 & 1755 & 0.084 \\
\hline $\begin{array}{l}\text { Working experience } \\
\text { (years) }\end{array}$ & 12.72 & 8.82 & 12.51 & 9.01 & 13.12 & 8.42 & $-2.324^{a}$ & - & 0.020 \\
\hline Total QOL score & 6.64 & 1.57 & 7.18 & 1.36 & 5.58 & 1.40 & 23.064 & 1755 & $<.001$ \\
\hline
\end{tabular}


Table 2

Independent correlates of depression by multiple logistic regression analysis

\begin{tabular}{|llll|}
\hline Variables & \multicolumn{3}{l}{ Multiple logistic regression analysis } \\
\cline { 2 - 4 } & OR & $95 \%$ Cl & P value \\
\hline Working in tertiary hospitals & 1.292 & $0.951-1.775$ & 0.101 \\
\hline Taking care of infected patients & 1.440 & $1.031-2.012$ & $\mathbf{0 . 0 3 2}$ \\
\hline Current smoker & 3.143 & $1.020-9.690$ & $\mathbf{0 . 0 4 6}$ \\
\hline Working experience (years) & 1.008 & $0.997-1.019$ & 0.168 \\
\hline Bolded values: $\mathrm{P}<0.05 ; \mathrm{Cl}$ : confidential interval; OR: odds ratio; QOL: Quality of Life \\
\hline
\end{tabular}

\section{Discussion}

To the best of our knowledge, this was the first study that examined the prevalence, demographic and clinical factors associated with depression among ENT nurses during the COVID-19 pandemic. Some studies, however, examined the epidemiology of depression among health professionals in China. For example, a study found that in early stage of the COVID-19 outbreak (at the end of January 2020), 50.4\% of frontline medical workers working in Wuhan and the surrounding areas of Hubei province reported depression as measured by the PHQ-9 with a cut-off value of 5 (Lai et al., 2020). Another similar study used the same cut off value in the PHQ-9 and found that the prevalence of depression among healthcare workers in Wuhan were 36.9\% in early stage of the COVID-19 outbreak (between January 29 and February 4, 2020) (Kang et al., 2020). In contrast, the prevalence of depression among frontline medical healthcare workers was $12.2 \%$ as assessed by the PHQ-4 with a lower cut-off value of 3 at later stage of the COVID-19 outbreak (from February 19 to March 6, 2020) (Zhang et al., 2020). Our findings emerging from this study $(33.75 \% ; 95 \% \mathrm{Cl}$ :

31.59\%-35.97\%) were similar to some (Kang et al., 2020), but not all studies (Lai et al., 2020, Zhang et al., 2020). Due to the use of different measurement tools on depression, direct comparisons between these studies should be interpreted with caution.

In ENT unit, some asymptomatic and pre-symptomatic patients with COVID-19 may seek help for anosmia (i.e., loss of sense of smell) which was a common infection symptom (Hopkins et al., 2020). In addition, auxiliary examinations of the nasal passages and upper airway, intubation and administration of respiratory treatment may induce cough, nausea, sneezing or vomiting (Lu et al., 2020). The nasal pillow masks for patients with obstructive sleep-apnea may cause airborne virus transmission due to loose sealing (Tran et al., 2012). For instance, in the 2003 SARS outbreak clusters of nosocomial infections were observed among healthcare workers during airway manipulation (JAMA, 2003). All these factors could increase the likelihood of COVID-19 infection for ENT nurses, and subsequently lead to common mental health problems, such as depression.

Similar with previous findings (Lai et al., 2020), frontline ENT nurses who provided direct patient care for COVID-19 patients were more likely to have depression. During the COVID-19 outbreak ENT nurses needed to 
do the shift duty and usually worked longer hours than usual, which may lead to job dissatisfaction, and high level of perceived stress. In addition, all health professionals must have at least two weeks quarantine after they finished providing care to COVID-19 patients, which may put them in anxiety state and guilty feelings due to social stigma on their families. All these factors could substantially increase the risk of depression. Previous studies found that smoking was associated with higher risk of physical diseases and mental problems (e.g., depression) (Chang et al., 2020, Fluharty et al., 2017, Mathew et al., 2017). We found that depressed ENT healthcare workers were more likely to smoke, which echoed previous findings (Nilan et al., 2019, Schneider et al., 2019)

According to the distress/protection QOL model (Voruganti et al., 1998), QOL was closely associated with the interaction between protective (e.g., high self-esteem and good social support) and distressing factors (e.g., physical and mental distress). We found that ENT nurses with depression had a lower QOL compared to the those without, which is consistent with previous findings (Benedek et al., 2007, Mammen and Faulkner, 2013). This could be explained by the negative health outcomes of depression, such as impaired psychosocial functioning, and somatic symptoms (e.g., fatigue, loss of appetite or weight, and insomnia) (Malhi and Mann, 2018, Rakofsky et al., 2013, Parisi et al., 2014).

The strengths of this study include the large sample size and the use of standardized instruments. Nevertheless, several limitations should be addressed. First, the use of cross-sectional survey indicated that the causality of demographic and clinical variables and depression could not be established. Second, data were collected by online self-report survey, therefore, participants might misunderstand some of the questions being asked. Third, due to logistical reasons, some factors related to depression in ENT nurses, such as lifestyles, perceived family support, and sleep-related variables were not obtained.

\section{Conclusions}

In conclusion, depression was common among ENT nurses during the COVID-19 pandemic in China. Considering the negative impact of depression on QOL and care quality, regular screening for depression should be conducted for ENT nurses and timely treatments should be provided for those in need.

\section{Declarations}

\section{Consent for publication}

Not applicable.

\section{Ethical Approval and Consent to participate}

This study was approved by the Institutional Review Board of the University of Macau (BSERE20-APP002FHS) and all participating hospitals. All the study procedures were carried out in accordance with relevant guidelines. All participants provide informed consent in the study. 


\section{Availability of data and material}

The data of the investigation will be made publicly available if necessary.

\section{Competing Interests}

The authors have no conflicts of interest to declare.

\section{Sources of Funding}

The study was supported by the National Science and Technology Major Project for investigational new drug (2018ZX09201-014), the Beijing Municipal Science \& Technology Commission (No. Z181100001518005), and the University of Macau (MYRG2019-00066-FHS).

\section{Author Contributors}

(I) Conception and design: Feng-Rong An, Yu-Tao Xiang.

(II) Administrative support: Yue Li, Fengrong An, Yutao Xiang.

(III) Provision of study materials or patients: Zi-Rong Tian, Xiaomeng Xie, Xiu-Ya Li, Yue Li.

(IV) Collection and assembly of data: Zi-Rong Tian, Xiaomeng Xie, Xiu-Ya Li, Yue Li,

(V) Data analysis and interpretation: Qinge Zhang, Yanjie Zhao, Chun Wang, Haiyang Yu, Teris Cheung.

(VI) Manuscript writing: All authors.

(VII) Final approval of manuscript: All authors.

\section{Acknowledgements}

None.

\section{References}

1. BENEDEK DM, FULLERTON C, URSANO RJ. First responders: mental health consequences of natural and human-made disasters for public health and public safety workers. Annu Rev Public Health. 2007;28:55-68.

2. CHANG ET, LAU EC, MOOLGAVKAR SH. 2020. Smoking, air pollution, and lung cancer risk in the Nurses' Health Study cohort: time-dependent confounding and effect modification. Crit Rev Toxicol, 1-12. 
3. CHEN M, QU SHENG,L, S. Diagnostic test of screening depressive disorder in general hospital with the Patient Health Questionnaire (in Chinese). Chinese Mental Health. 2015;29:241-5.

4. FLUHARTY M, GRABSKI TAYLOR,AE, M. \& MUNAFO MR. The Association of Cigarette Smoking With Depression and Anxiety: A Systematic Review. Nicotine Tob Res. 2017;19,:3-13.

5. GAO K, SU M, SWEET, J. \& CALABRESE JR. Correlation between depression/anxiety symptom severity and quality of life in patients with major depressive disorder or bipolar disorder. J Affect Disord. 2019;244:9-15.

6. HOPKINS C, SURDA P, KUMAR N. 2020. Presentation of new onset anosmia during the COVID-19 pandemic. Rhinology.

7. JAMA. Cluster of Severe Acute Respiratory Syndrome Cases Among Protected Health-Care WorkersToronto, Canada, April 2003. JAMA. 2003;289:2788-9.

8. KANG L, CHEN MA,S, WANG MYANG,J, LI Y, YAO R, BAI L, CAI H, XIANG Z, YANG B, ZHANG HU,S, WANG K, MA G, C. \& LIU Z. 2020. Impact on mental health and perceptions of psychological care among medical and nursing staff in Wuhan during the 2019 novel coronavirus disease outbreak: A crosssectional study. Brain Behav Immun.

9. KNIGHT MJ, AIR T, BAUNE BT. The role of cognitive impairment in psychosocial functioning in remitted depression. J Affect Disord. 2018;235:129-34.

10. LAI J, WANG MA,S, CAI Y, WEI ZHU,J, CHEN NWU,JDU,H, LI T, KANG RTAN,H, HUANG LYAO,L, LIU MWANG,HWANG,G, Z. \& HU S. Factors Associated With Mental Health Outcomes Among Health Care Workers Exposed to Coronavirus Disease 2019. JAMA Netw Open. 2020;3:e203976.

11. LI F, WU JF, NING MAI,XH, ZHENG KCHEN,KY,CHAO,L, X. Internalized Homophobia and Depression in Homosexuals: The Role of Self-concept Clarity (in Chinese). Chinese Journal of Clinical Psychology. 2016;24:475-9.

12. LIANG D, FAN G. 2020. Social Support and User Characteristics in Online Diabetes Communities: An InDepth Survey of a Large-Scale Chinese Population. Int J Environ Res Public Health, 17.

13. LU D, WANG H, YANG YU,R, H. \& ZHAO Y. Integrated infection control strategy to minimize nosocomial infection of coronavirus disease 2019 among ENT healthcare workers. J Hosp Infect. 2020;104:454-5.

14. MALHI GS, MANN JJ. Depression Lancet. 2018;392:2299-312.

15. MAMMEN G, FAULKNER G. Physical activity and the prevention of depression: a systematic review of prospective studies. Am J Prev Med. 2013;45:649-57.

16. MATHEW AR, HOGARTH L, LEVENTHAL AM, COOK, J. W. \& HITSMAN B. Cigarette smoking and depression comorbidity: systematic review and proposed theoretical model. Addiction. 2017;112:40112.

17. NHS. 2020. Coronavirus: Dr El-Hawrani, the NHS and the death of facts [Online]. Available: https://www.nhs.uk/profiles/consultant/4644578 [Accessed].

18. NILAN K, MCKEEVER TM, MCNEILL A, RAW M, MURRAY RL. Prevalence of tobacco use in healthcare workers: A systematic review and meta-analysis. PLoS One. 2019;14:e0220168.

19. PARISI JM, XIA J, XUE SPIRA,AP, RIEGER QL, M. L., REBOK, G. W. \& CARLSON MC. The Association Between Lifestyle Activities and Late-Life Depressive Symptoms. Act Adapt Aging. 2014;38:1-10. 
20. RAKOFSKY JJ, SCHETTLER PJ, KINKEAD BL, FRANK E, JUDD LL, RUSH KUPFER,DJ, THASE AJ, M. E., YONKERS, K. A. \& RAPAPORT MH. The prevalence and severity of depressive symptoms along the spectrum of unipolar depressive disorders: a post hoc analysis. J Clin Psychiatry. 2013;74:1084-91.

21. REP MMMW. Cluster of severe acute respiratory syndrome cases among protected health-care workersToronto, Canada, April 2003. MMWR Morb Mortal Wkly Rep. 2003;52:433-6.

22. SCHNEIDER A, BAK M, HOYLE MAHONEY,C, KELLY L, ATHERTON M, I. M. \& KYLE RG. Health-related behaviours of nurses and other healthcare professionals: A cross-sectional study using the Scottish Health Survey. J Adv Nurs. 2019;75:1239-51.

23. SKEVINGTON SM, LOTFY M, O'CONNELL KA, GROUP W. The World Health Organization's WHOQOLBREF quality of life assessment: psychometric properties and results of the international field trial. A report from the WHOQOL group. Qual Life Res. 2004;13:299-310.

24. TRAN K, CIMON K, SEVERN M, PESSOA-SILVA CL, CONLY J. Aerosol generating procedures and risk of transmission of acute respiratory infections to healthcare workers: a systematic review. PLoS One. 2012;7:e35797.

25. VORUGANTI L, HESLEGRAVE R, AWAD, A. G. \& SEEMAN MV. Quality of life measurement in schizophrenia: reconciling the quest for subjectivity with the question of reliability. Psychol Med. 1998;28:165-72.

26. WANG D, ZHU HU,BHU,C, LIU F, CHENG XZHANG,JWANG,BXIANG,H, XIONG Z, ZHAO Y, LI Y, WANG Y, X. \& PENG Z. 2020. Clinical Characteristics of 138 Hospitalized Patients With 2019 Novel CoronavirusInfected Pneumonia in Wuhan, China. JAMA.

27. WITTKAMPF KA, NAEIJE L, SCHENE, A. H., HUYSER, J. \& VAN WEERT HC. Diagnostic accuracy of the mood module of the Patient Health Questionnaire: a systematic review. Gen Hosp Psychiatry. 2007;29:388-95.

28. WOO YS, KAKAR ROSENBLAT,JD, BAHK R, W.-M. \& MCINTYRE RS. Cognitive deficits as a mediator of poor occupational function in remitted major depressive disorder patients. Clinical Psychopharmacology Neuroscience. 2016;14:1.

29. WORLD HEALTH ORGANIZATION. 2020. The Coronavirus disease (COVID-19) outbreak. https://www.who.int (access March 30th 2020).

30. XI X, LIU YF. The appliation of Wechat platform and Wenjuanxing in cognitive training among psychiatric nurse, cleaning staff and patients (in Chinese). Nursing Practice Research. 2017;14:114-7.

31. XIA P, LI N, LIU HAU,KT, C. \& LU Y. Quality of life of Chinese urban community residents: a psychometric study of the mainland Chinese version of the WHOQOL-BREF. BMC Med Res Methodol. 2012;12:37.

32. XU J, XU, Q. H., WANG, C. M. \& WANG J. Psychological status of surgical staff during the COVID-19 outbreak. Psychiatry Res. 2020;288:112955.

33. ZHANG WR, YIN WANG,K, ZHAO L, XUE WF, PENG Q, MIN M, TIAN BQ, YANG QLENG,HX,DU,JL,CHANG,H, LI Y, SHANGGUAN W, HAN FF,YAN,TY,DONG,HQ, COSCI YWANG,YP, F. \& WANG, H. X. 2020. Mental Health and Psychosocial Problems of Medical Health Workers during the COVID-19 Epidemic in China. Psychother Psychosom, 1-9. 
34. ZHAO S, YANG LIN,QRAN,JMUSA,SS, WANG G, GAO WLOU,Y, YANG D, HE L, D. \& WANG MH. Preliminary estimation of the basic reproduction number of novel coronavirus (2019-nCoV) in China, from 2019 to 2020: A data-driven analysis in the early phase of the outbreak. Int J Infect Dis. 2020;92:214-7. 